\title{
Complication rates associated with 3-column osteotomy in 82 adult spinal deformity patients: retrospective review of a prospectively collected multicenter consecutive series with 2-year follow-up
}

\author{
Justin S. Smith, MD, PhD, ${ }^{1}$ Christopher I. Shaffrey, MD, ${ }^{1}$ Eric Klineberg, MD, ${ }^{2}$ \\ Virginie Lafage, PhD, ${ }^{3}$ Frank Schwab, MD, ${ }^{3}$ Renaud Lafage, MS, ${ }^{3}$ Han Jo Kim, MD, ${ }^{3}$ \\ Richard Hostin, MD, ${ }^{4}$ Gregory M. Mundis Jr., MD, ${ }^{5}$ Munish Gupta, MD, ${ }^{6}$ Barthelemy Liabaud, MD, ${ }^{3}$ \\ Justin K. Scheer, MD, ${ }^{7}$ Bassel G. Diebo, MD, ${ }^{3}$ Themistocles S. Protopsaltis, MD, ${ }^{8}$ \\ Michael P. Kelly, MD, ${ }^{6}$ Vedat Deviren, MD, ${ }^{9}$ Robert Hart, MD, ${ }^{10}$ Doug Burton, MD, ${ }^{11}$ \\ Shay Bess, MD, ${ }^{8}$ and Christopher P. Ames, MD, ${ }^{12}$ on behalf of the International Spine Study Group
}

\begin{abstract}
${ }^{1}$ Department of Neurosurgery, University of Virginia Medical Center, Charlottesville, Virginia; ${ }^{2}$ Department of Orthopaedic Surgery, University of California Davis, Sacramento; ${ }^{5}$ San Diego Spine Foundation, La Jolla; Departments of ${ }^{9}$ Orthopaedic Surgery and ${ }^{12}$ Neurosurgery, University of California San Francisco, California; ${ }^{3}$ Department of Orthopaedic Surgery, Hospital for Special Surgery, New York; ${ }^{8}$ Department of Orthopaedic Surgery, NYU Hospital for Joint Diseases, New York, New York; ${ }^{4}$ Department of Orthopaedic Surgery, Baylor Scoliosis Center, Plano, Texas; ${ }^{6}$ Department of Orthopaedic Surgery, Washington University, St Louis, Missouri; 'Department of Neurosurgery, University of Illinois at Chicago, Illinois; ${ }^{10}$ Department of Orthopaedic Surgery, Oregon Health \& Science University, Portland, Oregon; and ${ }^{11}$ Department of Orthopaedic Surgery, University of Kansas Medical Center, Kansas City, Kansas
\end{abstract}

OBJECTIVE Although 3-column osteotomy (3CO) can provide powerful alignment correction in adult spinal deformity (ASD), these procedures are complex and associated with high complication rates. The authors' objective was to assess complications associated with ASD surgery that included 3CO based on a prospectively collected multicenter database. METHODS This study is a retrospective review of a prospectively collected multicenter consecutive case registry. ASD patients treated with $3 \mathrm{CO}$ and eligible for 2-year follow-up were identified from a prospectively collected multicenter ASD database. Early ( $\leq 6$ weeks after surgery) and delayed ( $>6$ weeks after surgery) complications were collected using standardized forms and on-site coordinators.

RESULTS Of 106 ASD patients treated with 3CO, 82 (77\%; 68 treated with pedicle subtraction osteotomy [PSO] and 14 treated with vertebral column resection [VCR]) had 2-year follow-up (76\% women, mean age 60.7 years, previous spine fusion in $80 \%$ ). The mean number of posterior fusion levels was 12.9 , and $17 \%$ also had an anterior fusion. $A$ total of 76 early (44 minor, 32 major) and 66 delayed (13 minor, 53 major) complications were reported, with 41 patients $(50.0 \%)$ and 45 patients (54.9\%) affected, respectively. Overall, 64 patients (78.0\%) had at least 1 complication, and $50(61.0 \%)$ had at least 1 major complication. The most common complications were rod breakage (31.7\%), dural tear $(20.7 \%)$, radiculopathy $(9.8 \%)$, motor deficit $(9.8 \%)$, proximal junctional kyphosis (PJK, $9.8 \%)$, pleural effusion $(8.5 \%)$, and deep wound infection (7.3\%). Compared with patients who did not experience early or delayed complications, those who had these complications did not differ significantly with regard to age, sex, body mass index, Charlson Comorbidity Index, American Society of Anesthesiologists score, smoking status, history of previous spine surgery or spine fusion, or whether the 3 CO performed was a PSO or VCR ( $p \geq 0.06)$. Twenty-seven (33\%) patients had $1-11$ reoperations (total

ABBREVIATIONS ASA = American Society of Anesthesiologists; ASD = adult spinal deformity; $A$ SIA = American Spinal Injury Association; BMI = body mass index; CCI = Charlson Comorbidity Index; EBL = estimated blood loss; LEMS = Lower Extremity Motor Score; $\mathrm{LL}=$ lumbar lordosis; $\mathrm{PI}=$ pelvic incidence; $\mathrm{PI}$-LL = mismatch between $\mathrm{PI}$ and LL; PJK = proximal junctional kyphosis; PSO = pedicle subtraction osteotomy; PT = pelvic tilt; SRS = Scoliosis Research Society; SVA = sagittal vertical axis; TK = thoracic kyphosis; VCR = vertebral column resection; $3 \mathrm{CO}=3$-column osteotomy.

SUBMITTED July 19, 2016. ACCEPTED October 14, 2016.

INCLUDE WHEN CITING Published online February 17, 2017; DOI: 10.3171/2016.10.SPINE16849. 
of 44 reoperations). The most common indications for reoperation were rod breakage $(n=14)$, deep wound infection ( $n$ $=15)$, and PJK $(n=6)$. The 24 patients who did not achieve 2-year follow-up had a mean of 0.85 years of follow-up, and the types of early and delayed complications encountered in these 24 patients were comparable to those encountered in the patients that achieved 2-year follow-up.

CONCLUSIONS Among 82 ASD patients treated with 3CO, 64 (78.0\%) had at least 1 early or delayed complication (57 minor, 85 major). The most common complications were instrumentation failure, dural tear, new neurological deficit, PJK, pleural effusion, and deep wound infection. None of the assessed demographic or surgical parameters were significantly associated with the occurrence of complications. These data may prove useful for surgical planning, patient counseling, and efforts to improve the safety and cost-effectiveness of these procedures.

https://thejns.org/doi/abs/10.3171/2016.10.SPINE16849

KEY WORDS adult spinal deformity; complications; osteotomy; pedicle subtraction osteotomy; prospective; vertebral column resection

A LTHOUGH multiple studies have shown the potential for significant improvement in pain and disability with surgery for adult spinal deformity (ASD), ${ }^{11,12}$, 53,56,59-61 these procedures are associated with high rates of complications. ${ }^{47,53,54,57,61,63}$ Correction of ASD often relies upon the use of osteotomies that range from simple facet releases to 3-column osteotomies (3COs), which include pedicle subtraction osteotomy (PSO) and vertebral column resection (VCR). ${ }^{13,14,49}$ Use of $3 \mathrm{CO}$ is typically reserved for the most severe and often rigid deformities that cannot be readily corrected with other techniques, since these osteotomies are the most aggressive and have been associated with the highest rates of complications. ${ }^{3,8,9,16,21,23,26,29,34,48,54,57,62}$

Multiple previous reports have described $3 \mathrm{CO}$ techniques and have presented complications associated with these procedures. $3,6,8,10,13-15,52$ However, these studies have been limited by multiple factors, including retrospective collection of complications, relatively small numbers of patients, single-surgeon or single-center series, focus on only select types of complications, and lack of sufficient follow-up. An accurate and complete assessment of complications associated with $3 \mathrm{CO}$ procedures may prove useful for surgical planning, patient counseling, and efforts to improve the safety and cost-effectiveness of these procedures.

Our objective in the present study was to prospectively assess the rates of complications associated with ASD surgery that included 3CO with 2-year follow-up based on a multicenter study design that incorporated standardized data collection forms, on-site study coordinators, and regular auditing of data to help ensure complete and accurate reporting of complications. In addition, we provide assessment for associations between basic demographic and surgical parameters and the occurrence of complications.

\section{Methods}

\section{Patient Population}

This is a retrospective review of a prospectively collected multicenter registry of consecutive ASD patients. Patients were enrolled into an ongoing database through an IRB-approved protocol at 11 sites across the United States. At the time of enrollment, patients provided consent for participation. Database inclusion criteria are: age
$>18$ years and at least one of the following radiographic measures: scoliosis $\geq 20^{\circ}$, sagittal vertical axis (SVA) $\geq 5$ $\mathrm{cm}$, pelvic tilt $(\mathrm{PT}) \geq 25^{\circ}$, and thoracic kyphosis $(\mathrm{TK}) \geq$ $60^{\circ}$. At the time of study enrollment, patients were classified into either operative or nonoperative treatment groups based on the initial management approach. For patients undergoing operative treatment, the procedural choice and instrumentation used, as well as the extent of surgery and operative objectives, were at the discretion of the operating surgeon. The present study focuses on patients who underwent operative treatment that included a $3 \mathrm{CO}$ (either PSO or VCR) and who had 2-year follow-up after surgical treatment at the time of data extraction. In addition, a summary of complications for patients who were treated with a $3 \mathrm{CO}$ but did not achieve 2-year follow-up is provided as a means of assessing for confounding effects on reported types and rates of complications that may be introduced by patients lost to follow-up.

\section{Data Collection and Radiographic Assessment}

As part of the standardized registry protocol, data collection forms were used to collect patient demographics, imaging studies, comorbidities, details of surgical procedures, and complications. During the perioperative period and at follow-up time intervals, patients were assessed for complications based on examination, imaging, and questioning. On-site study coordinators at each center assisted in collecting complications and, in combination with regular data auditing from the central core facility, helped to ensure accurate reporting and complete collection of complications. Coordinators assisted in collecting complications at each site through meeting with patients at clinic visits, communicating with the treating physicians, and reviewing imaging reports and clinic records. At each follow-up time point, the standardized complication data collection form was completed to indicate whether any of the listed complications had occurred. In addition, since no form can include every complication that can possibly occur, providers and coordinators were instructed to be vigilant of other less common complications not listed on the form and to report these as well. The deidentified data from each site were sent to a single center where the entire data sets were summarized and analyzed and the complications were reviewed. 
Complications were classified as early or delayed and as minor or major. Early complications were those occurring within 6 weeks of surgery, and delayed complications were those occurring between 6 weeks after surgery and the time of last follow-up. A complication was classified as major if it substantially prolonged hospitalization, involved an invasive intervention, had prolonged or permanent morbidity, or resulted in death. For example, implant prominence or a painful implant that did not require revision was classified as minor, whereas if a revision procedure was required, it was classified as major. Any complication that resulted in the need for reoperation was considered major. In addition, complications that occurred in association with reoperations were also included in the present study. All complications were audited by a panel of surgeons and classified as minor versus major based on the above criteria. We do not currently employ strict criteria for factors such as the number of days that constitute a prolonged hospitalization, since this can vary substantially based on the specific complication, treatment required, and clinical situation. A complication that required multiple returns to the operating room was considered a single complication, and the number of reoperations was added to the total associated with the respective complication category. For example, a deep wound infection that was managed with 3 returns to the operating room for debridement was a considered a single major complication, and these 3 reoperations were reported in association with the deep wound infection category.

All cases of rod fracture were classified as major complications, regardless of whether the patient had undergone a revision procedure to address this complication at the time of data extraction. Although a small subset of rod fractures may follow a relatively benign course, our experience has been that the distinct majority ultimately need a revision procedure. Although one could argue for attempting to split these into minor versus major, given that CT imaging was not available for all cases to more clearly assess fusion status, we decided to err on the side of upgrading these to the major category.

It remains controversial whether "excessive" blood loss without apparent sequelae should be considered a complication in spine surgery. Since blood loss was not clearly associated with the occurrence of any complications in the present series, we chose to present estimated blood loss (EBL) as a descriptive variable, rather than as a potential complication based on an arbitrary threshold.

Full-length free-standing posteroanterior and lateral spine radiographs were obtained at specified time intervals: preoperative, 6 weeks postoperative (window of 1-7 weeks), 1 year postoperative (window of 10-14 months), and 2-years postoperative (24-30 months). Radiographs were analyzed using validated software (Spineview, ENSAM Laboratory of Biomechanics). ${ }^{17,46}$ All radiographic measures were performed at a central location based on standard techniques ${ }^{2,43}$ including: scoliosis, lumbar lordosis (LL, Cobb angle between superior endplate of L-1 and superior endplate of S-1), sagittal vertical axis (SVA), pelvic tilt (PT), pelvic incidence (PI), and mismatch between PI and LL (PI-LL), as previously described. ${ }^{2}$ Patients were classified based on the Scoliosis Research Society (SRS)-
Schwab adult thoracolumbar spinal deformity classification (Fig. 1)..$^{50,55,65}$

\section{Data and Statistical Analysis}

Frequency distributions and summary statistics were calculated for all variables. The data were assessed using the Shapiro-Wilk test for normality. For categorical variables, cross-tabulations were generated and Fisher's exact or Pearson chi-square tests were used to compare distributions. For continuous variables with normal distribution, statistical comparisons were performed using Student ttests and ANOVA tests. For data that were not normally distributed, the Mann-Whitney U-test was used to determine statistical associations. Statistical analyses were 2-sided, and $\mathrm{p}<0.05$ was considered statistically significant.

\section{Results}

\section{Patient Population}

Following database enrollment, 174 patients were treated with a 3CO; 165 of these patients were treated with a $3 \mathrm{CO}$ at the time of initial enrollment, and 9 were treated with a $3 \mathrm{CO}$ as part of a revision procedure subsequent to the initial procedure at the time of database enrollment (Fig. 1). Excluding patients who were not yet eligible for 2-year follow-up $(\mathrm{n}=59)$ and those with incomplete baseline data $(\mathrm{n}=9)$, a total of 106 patients met the inclusion criteria. Note that since database enrollment is an ongoing process, the 59 patients not yet eligible for 2-year followup were those patients for whom a minimum of 2 years had not yet elapsed between the time of surgery and the point at which data were extracted for the present study. Of the patients meeting inclusion criteria, 82 (77\%) achieved 2-year follow-up, and these patients are the primary focus of the present study. These 82 cases were contributed by 12 surgeons (contribution per surgeon ranged from 1 to 23 cases) and were from 10 centers. The patients who did $(n=82)$ and did not $(n=24)$ achieve 2-year follow-up did not significantly differ with regard to age $(p=0.84)$, sex $(\mathrm{p}=0.30)$, body mass index (BMI) $(\mathrm{p}=0.96)$, Charlson Comorbidity Index $(\mathrm{CCI})(\mathrm{p}=0.56)$, American Society of Anesthesiology (ASA) score $(\mathrm{p}=0.79)$, proportion with previous spine fusion $(\mathrm{p}=0.76)$, and whether the $3 \mathrm{CO}$ was a PSO or a VCR $(\mathrm{p}=1.00)$.

Demographic and operative parameters for the 82 study patients are summarized in Table 1 . The mean age was 60.7 years, and the majority of patients $(76 \%)$ were women. The mean BMI of 29.0 falls within the overweight category and borders on obesity. The mean $\mathrm{CCI}^{18}$ and ASA scores were 2.1 and 2.5, respectively. The majority of patients had a history of previous spine surgery (85.4\%), and most $(80.0 \%)$ had been previously treated with spine fusion. Of the 82 study patients, 68 were treated with PSO and 14 were treated with VCR. The most common PSO levels were L-3 ( $n=30)$, L-4 ( $=15)$, and L-2 $(n=9)$. VCR levels ranged from T-6 through L-5, and the most common level was T-12 $(n=3)$. Two 3COs were performed in 5 patients (6.1\%) (L-1 and L-2 VCRs, L-2 and L-3 PSOs, L-2 and L-5 VCRs, T-6 and T-7 VCRs, and T- 8 and T-9 VCRs), and three $3 \mathrm{CO}$ s were performed in 1 patient (1.2\%) (T-9, L-3, and L-4 VCRs). Based on study inclusion criteria, all 


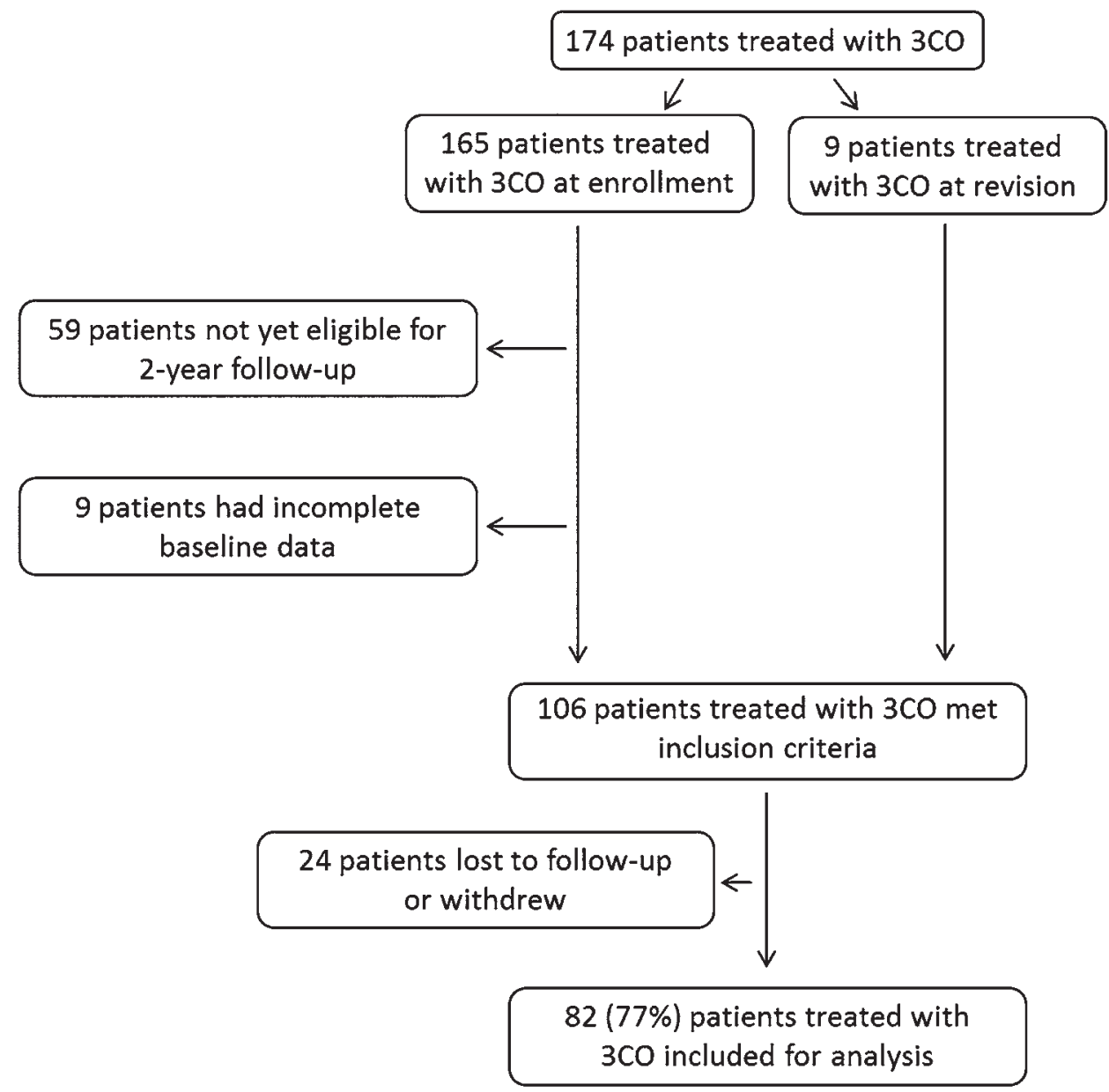

FIG. 1. Flow diagram for patient selection.

patients underwent a posterior surgical procedure, and the mean number of instrumented vertebral levels was 12.9. A subset of these patients (17.1\%) also underwent an anterior procedure. The procedure included a decompression in the majority of patients $(72.0 \%)$. Mean operating room time and estimated blood loss (EBL) were 8.0 hours and 3.3 L, respectively, and the mean length of hospital stay was 10.0 days. None of the assessed demographic or operative parameters differed significantly between the patients treated with PSO versus those treated with VCR, except for a modestly but significantly greater number of instrumented posterior vertebral levels in the VCR group (14.9 vs 12.5 levels, $p=0.042$; Table 1 ).

Based on the SRS-Schwab ASD classification (Fig. 2 upper), ${ }^{51,55,65}$ almost one-half (47.6\%) of patients had coronal curve type "N," which reflects a spinal deformity that does not include any coronal curves greater than $30^{\circ}$ (Fig. 2 lower). The remaining patients had coronal curves greater than $30^{\circ}$ in the thoracic (1.2\%), thoracolumbar/lumbar (31.7\%), or both thoracic and thoracolumbar (19.5\%) regions. The SRS-Schwab sagittal modifier grades (Fig. 2 upper) for the study population reflect substantial sagittal spinopelvic malalignment (Fig. 2 lower). For each modifier, more than $80 \%$ of patients demonstrated moderately $(+)$ or severely $(++)$ abnormal values (Fig. 2 lower).

\section{Early and Delayed Complications by General Category}

Rates of early and delayed complications are summarized based on general complication categories in Table 2 . A total of 76 early (44 minor and 32 major) and 66 delayed (13 minor and 53 major) complications were identified. The mean numbers of early, delayed, and total complications per patient were $0.93,0.80$, and 1.73 , respectively. Overall, 41 patients (50\%) had at least 1 early complication, $45(54.9 \%)$ had at least 1 delayed complication, and 64 patients $(78.0 \%)$ were affected by at least 1 early or delayed complication (Table 2). At least 1 early or delayed minor complication occurred in 37 patients (45.1\%), and at least 1 early or delayed major complication occurred in 50 patients $(61.0 \%)$. Figure 3 summarizes the distribution of patients based on the numbers of minor and major complications that occurred. Although $22 \%$ of patients did not experience any early or delayed complications from surgery through 2-year follow-up, the remaining patients had from 1 to 9 complications (Fig. 3).

Based on general complication categories, the most common complications were implant related (2 minor and 31 major), neurological ( 8 minor and 16 major), operative (18 minor and 1 major), cardiopulmonary (10 minor and 9 major), radiographic (5 minor and 13 major), and infection (4 minor and 9 major) (Table 2). 
TABLE 1. Demographic and operative parameters for 82 adults surgically treated for spinal deformity stratified and compared based on osteotomy type

\begin{tabular}{|c|c|c|c|c|}
\hline \multirow[b]{2}{*}{ Parameter } & \multicolumn{3}{|c|}{ 3-Column Osteotomy Type } & \multirow{2}{*}{$\begin{array}{c}\text { All } \\
\text { Patients }\end{array}$} \\
\hline & PSO & VCR & $p$ Value & \\
\hline No. of patients (\%) & $68(83)$ & $14(17)$ & - & 82 \\
\hline Female/male & $50: 18$ & $12: 2$ & 0.50 & $62: 20$ \\
\hline Mean age, yrs (SD) & $61.1(11.2)$ & $58.6(13.5)$ & 0.46 & $60.7(11.6)$ \\
\hline Mean BMI (SD) & $28.9(5.9)$ & $29.4(6.5)$ & 0.81 & $29.0(6.0)$ \\
\hline Mean CCl (SD) & $2.0(1.9)$ & $2.5(2.1)$ & 0.41 & $2.1(1.9)$ \\
\hline Mean ASA (SD) & $2.5(0.6)$ & $2.7(0.6)$ & 0.19 & $2.5(0.6)$ \\
\hline Current smoker (\%) & 3.2 & 0.0 & 1.00 & 2.6 \\
\hline $\begin{array}{l}\text { Previous spine sur- } \\
\text { gery }(\%)\end{array}$ & 88.2 & 71.4 & 0.21 & 85.4 \\
\hline $\begin{array}{l}\text { Previous spine fusion } \\
\quad(\%)\end{array}$ & 82.1 & 69.2 & 0.28 & 80.0 \\
\hline Anterior procedure (\%) & $11(16.2)$ & $3(21.4)$ & 0.70 & $14(17.1)$ \\
\hline Mean levels (SD) & $1.9(0.8)$ & $2.0(1.0)$ & 0.87 & $1.9(0.8)$ \\
\hline $\begin{array}{l}\text { Posterior procedure } \\
(\%)\end{array}$ & $82(100)$ & $82(100)$ & - & $82(100)$ \\
\hline Mean levels (SD) & $12.5(4.1)$ & $14.9(3.1)$ & $0.042^{*}$ & $12.9(4.0)$ \\
\hline Decompression (\%) & 72.1 & 71.4 & 1.00 & 72.0 \\
\hline $\begin{array}{l}\text { Mean OR time, hrs } \\
\quad(\mathrm{SD})\end{array}$ & $7.9(2.7)$ & $8.3(2.7)$ & 0.581 & $8.0(2.7)$ \\
\hline Mean EBL, L (SD) & $3.4(2.5)$ & $3.0(1.7)$ & 0.921 & $3.3(2.3)$ \\
\hline Mean LOS, days (SD) & $9.8(6.7)$ & $11.1(6.7)$ & 0.471 & $10.0(6.7)$ \\
\hline $\begin{array}{l}\text { EBL = estimated blood Il } \\
\text { room. } \\
\text { Boldface type indicates } \\
{ }^{*} \text { Mann-Whitney U-test. }\end{array}$ & tical sig & ce. & & \\
\hline
\end{tabular}

\section{Early and Delayed Complications by Subtype}

Table 3 provides a summary of the subtypes of reported complications for each of the general complication categories from Table 2 . The most common implant-related complication was rod breakage, which occurred in 26 patients and led to reoperation in 14 patients. The most common neurological complications were radiculopathy and motor deficit, which each occurred in 8 patients $(9.8 \%)$ and led to 4 reoperations (radiculopathy, 3; motor deficit, 1). Dural tear occurred in 17 patients (20.7\%) and accounted for the majority of operative complications but notably did not require any reoperations in this series. The most common cardiopulmonary complications were pleural effusion (8.5\%), pulmonary embolism (3.7\%), deep venous thrombosis (3.7\%), arrhythmia (2.4\%), and congestive heart failure (2.4\%). Proximal junctional kyphosis (PJK) accounted for $44.4 \%$ of the radiographic complications and was associated with the need for reoperation in 6 patients. Deep wound infection was the most common type of infection reported and occurred in 6 patients (7.3\%). A total of 15 reoperations were associated with the treatment of these deep wound infections. The most common wound complication (excluding infection) was dehiscence, which occurred in 6 patients (7.3\%). Gastrointestinal and vascular complications were less common and included ileus and coagulopathy, respectively.

\section{Assessment of Factors Associated With Complication Occurrence}

Compared with patients who did not experience early or delayed complications, those who had these complications did not differ significantly with regard to age, sex, BMI, CCI, ASA, smoking status, history of previous spine surgery or spine fusion, or whether the $3 \mathrm{CO}$ performed was a PSO or VCR ( $\geq \geq 0.06$; Table 4$)$. The percentages of patients affected by complications (Fig. 4) and the mean numbers of complications per patient (Fig. 5) did not differ significantly based on patient age $(\mathrm{p} \geq 0.61)$. In addition, the overall complication rates did not differ significantly based on surgeon $(p=0.65)$ or contributing site $(p=0.71)$.

\section{Complications in Patients Not Achieving 2-Year Follow-Up}

Reported early and delayed complications for the 24 patients who did not achieve 2-year follow-up are summarized in Table 5. The mean duration of follow-up for these patients was 0.85 years ( 3 had no recorded follow-up beyond discharge; 7 had no follow-up beyond 6 weeks; 14 had no follow-up beyond 1 year). Among these patients, $10(41.7 \%)$ had at least 1 early complication (8 minor and 2 major), which is comparable to the corresponding percentage for those who did achieve 2-year follow-up (50\%; Table 2). Notably, the distribution and types of early and delayed complications encountered in those lost to followup were comparable to those who achieved 2-year followup (Tables 2 and 5).

\section{Discussion}

This study provides an assessment of complications associated with surgical treatment for ASD that included a $3 \mathrm{CO}$ based on a prospective, multicenter design with 2-year follow-up. To help ensure accurate and complete collection of complications, standardized data collection forms were used, each contributing center had at least 1 on-site study coordinator, and regular central auditing of the data was performed. Although several previous studies have reported on complications associated with $3 \mathrm{CO}$ for the treatment of ASD, these studies have been limited by multiple factors, including retrospective collection of complications, relatively small numbers of patients, single-surgeon or single-center series, focus on only selected types of complications, and lack of sufficient follow-up. ${ }^{3-5,8,9,13 \text {, }}$ $16,19-21,23,29,33,34,57,58,62$ The present study was designed in an attempt to overcome many of these limitations to provide a complete and detailed assessment of the types and incidences of complications encountered in the treatment of ASD with 3CO from the time of surgery through 2-year follow-up. These data may prove useful for surgical planning, patient counseling, and for efforts to improve the safety and cost-effectiveness of these procedures.

A total of 142 complications (57 minor and 85 major) were reported in this series, and $78 \%$ of patients experienced at least 1 complication from the time of surgery through 2-year follow-up. These complication rates are higher than those reported in many previous studies, which is likely reflective of the study design, focus on complication collection, and the length of follow-up. Importantly, the majority of reported complications likely 
Coronal curve types

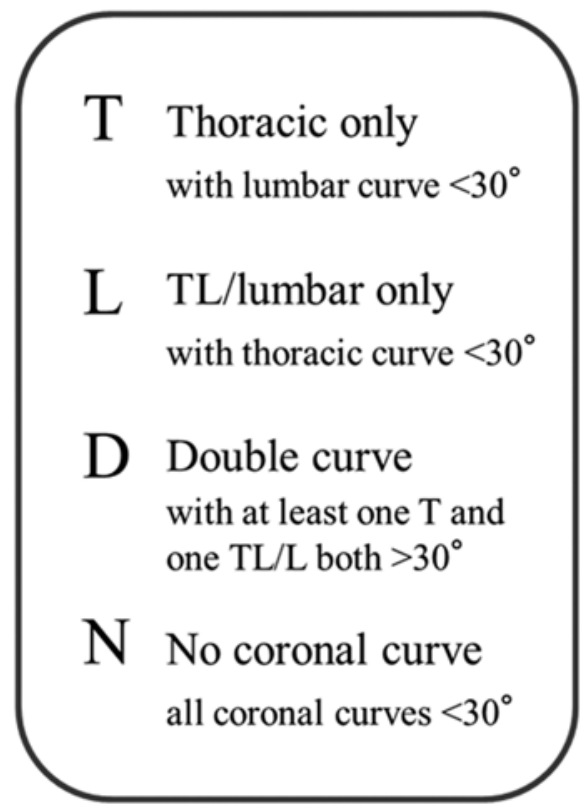

Sagittal modifiers

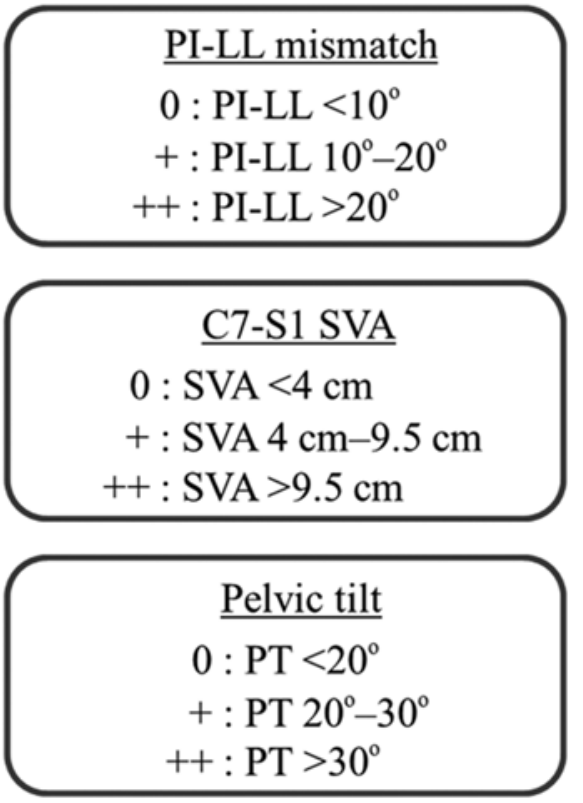

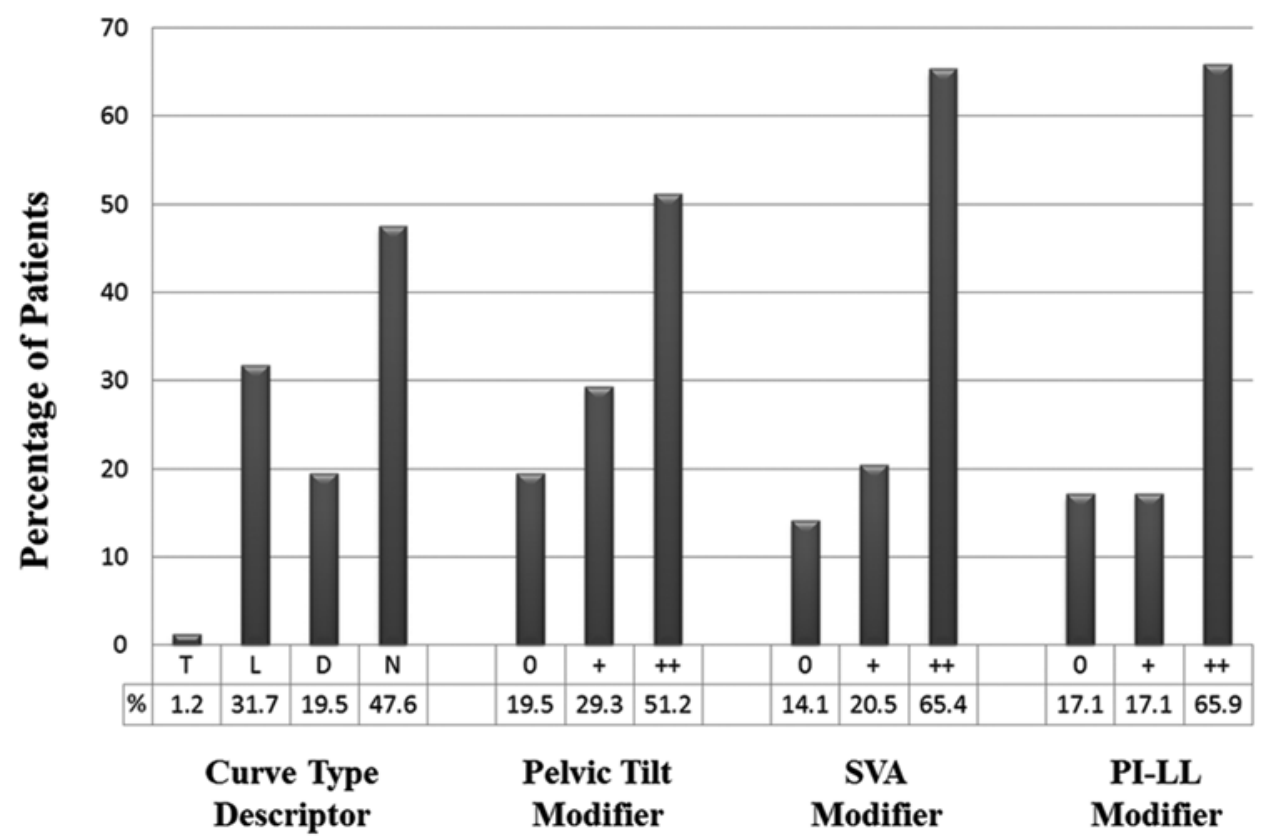

FIG. 2. Summary of the SRS-Schwab classification for adult thoracolumbar spinal deformity (upper $)^{50}$ and distribution of patients in the present study by SRS-Schwab curve type descriptor and sagittal spinopelvic modifier classification (lower). $\mathrm{L}=$ lumbar; $\mathrm{PI}$ $\mathrm{LL}=$ pelvic incidence to lumbar lordosis mismatch; $\mathrm{PT}=$ pelvic tilt; SVA = sagittal vertical axis; $\mathrm{TL}=$ thoracolumbar; $\mathrm{T}=$ thoracic.

had limited to no impact on the ultimate outcomes of these patients. For example, a dural tear that is primarily repaired intraoperatively or a postoperative ileus that is treated medically would not typically be expected to result in long-term negative impact on clinical outcomes. Nevertheless, it is important to recognize that there are complications that can have a permanent impact and that even those without residual long-term effects can cause added patient pain and distress, increase the need for invasive interventions (including reoperation), prolong hos- pital stays and recovery, and substantially increase the cost of these treatments. ${ }^{39-42,72}$ For example, although the occurrence of rod breakage, the most common complication observed in the present study, can typically be effectively treated with replacement of instrumentation and revision arthrodesis, such treatment requires the patient to undergo an additional surgical procedure with exposure to further risks of complications, necessitates additional recovery time, and diminishes the cost-effectiveness of treatment. ${ }^{72}$ 


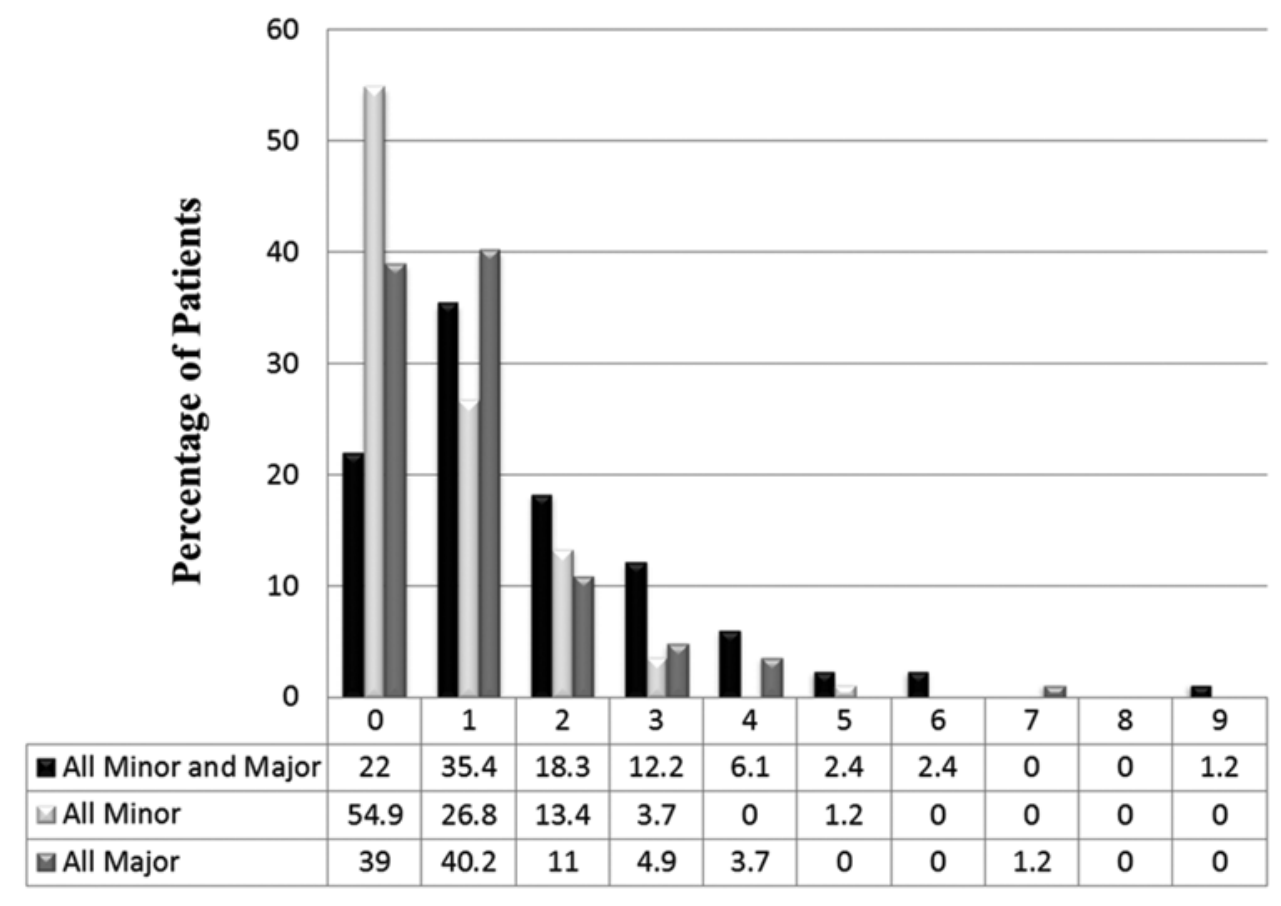

Number of Complications

FIG. 3. Distribution of patients based on the numbers of minor and major complications that occurred (from 0 to 9). Complications include those occurring perioperatively through the 2-year follow-up time period.

A recent report by Lenke and colleagues ${ }^{37}$ provided preoperative and serial postoperative neurological assessment of a series of 272 patients who were treated with surgery for complex ASD at 15 sites worldwide. At hospital

TABLE 2. Rates of complications in 82 adults with surgical treatment that included a 3-column osteotomy for spinal deformity with 2-year follow-up

\begin{tabular}{lccc}
\hline \multirow{2}{*}{$\begin{array}{c}\text { Complication } \\
\text { Category }\end{array}$} & $\begin{array}{c}\text { Early } \\
(\leq 6 \mathrm{wks})\end{array}$ & $\begin{array}{c}\text { Delayed } \\
(>6 \mathrm{wks})\end{array}$ & Total \\
\cline { 2 - 4 } Implant & $1 / 0(1.2)$ & $1 / 31(39.0)$ & $2 / 31(40.2)$ \\
\hline Neurologic & $4 / 11(18.3)$ & $4 / 5(11.0)$ & $8 / 16(29.3)$ \\
\hline Operative & $18 / 1(23.2)$ & $0 / 0(0.0)$ & $18 / 1(23.2)$ \\
\hline Cardiopulmonary & $9 / 8(20.7)$ & $1 / 1(2.4)$ & $10 / 9(23.2)$ \\
\hline Radiographic & $1 / 3(4.9)$ & $4 / 10(17.1)$ & $5 / 13(22.0)$ \\
\hline $\begin{array}{l}\text { Infection } \\
\text { Wound (exclud- } \\
\text { ing infection) }\end{array}$ & $2 / 6(9.8)$ & $2 / 3(6.1)$ & $4 / 9(15.9)$ \\
\hline $\begin{array}{l}\text { Gastrointestinal } \\
\text { Vascular }\end{array}$ & $3 / 3(8.5)$ & $0 / 3(3.7)$ & $4 / 6(12.2)$ \\
\hline $\begin{array}{l}\text { Total (minor/ } \\
\text { major) }\end{array}$ & $2 / 0(2.4)$ & $1 / 0(1.2)$ & $4 / 0(4.9)$ \\
\hline $\begin{array}{l}\text { Mean no. of com- } \\
\text { plications per } \\
\text { patient (minor/ } \\
\text { major) }\end{array}$ & $0.93(0.54 / 0.39)$ & $0.80(0.16 / 0.65)$ & $1.73(0.70 / 1.04)$ \\
\hline $\begin{array}{l}\text { No. of patients } \\
\text { affected (\%) }\end{array}$ & $41(50.0 \%)$ & $45(54.9 \%)$ & $64(78.0 \%)$ \\
\hline & & & $142(57 / 85)$ \\
\hline
\end{tabular}

discharge, $22.2 \%$ of the patients in that series showed a decline in American Spinal Injury Association (ASIA) Lower Extremity Motor Score (LEMS) compared with preoperative assessment. This rate of motor decline is approximately double that observed in the present study. This difference may be partially accounted for by the focus on particularly complex deformities in the study by Lenke and colleagues, which may be expected to result in greater risk of neurological compromise compared with a study such as the present study, which included a greater range of deformity complexities. In addition, Lenke and colleagues included detailed assessment of the ASIA LEMS that likely detected many mild and more subtle changes in neurological function that could readily go undetected without such formal assessment.

The present study did not identify any factors that were significantly associated with the occurrence of early or delayed complications, including patient demographics and operative parameters. It is notable that neither patient age nor comorbidities were significantly associated with occurrence of complications. Several previous studies have reported significantly higher complication rates in older patients undergoing treatment for ASD compared with younger patients. 3,54,61,62 In contrast, other studies have not found significantly higher complication rates in older patients. ${ }^{23,57}$ The reason for a lack of association between age and the incidence of complications in the present study may be due to the dominant types of complications encountered. For example, rod breakage was the most common complication, but the risk of this complication may derive more from the degree of biomechanical rod compromise across the $3 \mathrm{CO}^{\text {level }}{ }^{64}$ than from patient age. Oth- 
TABLE 3. Rates of complications in 82 adults with surgical treatment that included a 3-column osteotomy for spinal deformity with 2-year follow-up*

\begin{tabular}{|c|c|c|c|}
\hline \multirow[b]{2}{*}{$\begin{array}{c}\text { Complication } \\
\text { Category }\end{array}$} & \multicolumn{3}{|c|}{ No. of Complications, Major/Minor (\%) } \\
\hline & $\begin{array}{c}\text { Early } \\
\text { ( } \leq 6 \mathrm{wks})\end{array}$ & $\begin{array}{l}\text { Delayed } \\
\text { (>6 wks) }\end{array}$ & Total \\
\hline Implant & $1 / 0(1.2)$ & $1 / 31(39.0)$ & $2 / 31(40.2)$ \\
\hline Rod breakage & $0 / 0$ & 0/26 (14 reop) & $0 / 26(31.7)$ \\
\hline Implant prominence & $0 / 0$ & 1/1 (1 reop) & $1 / 1(2.4)$ \\
\hline Screw breakage & $0 / 0$ & $0 / 2$ & $0 / 2(2.4)$ \\
\hline $\begin{array}{l}\text { Implant loosening/ } \\
\text { dislodgement }\end{array}$ & $1 / 0$ & $0 / 0$ & $1 / 0(1.2)$ \\
\hline Rod dislodgement & $0 / 0$ & 0/1 (1 reop) & $0 / 1(1.2)$ \\
\hline $\begin{array}{l}\text { Screw nerve impinge- } \\
\text { ment }\end{array}$ & $0 / 0$ & 0/1 (1 reop) & $0 / 1(1.2)$ \\
\hline Neurological & 4/11 (18.3) & $4 / 5(11.0)$ & $8 / 16(29.3)$ \\
\hline Radiculopathy & 2/4 (3 reop) & $2 / 0$ & $4 / 4(9.8)$ \\
\hline Motor deficit & $0 / 5$ & 0/3 (1 reop) & $0 / 8(9.8)$ \\
\hline Nerve root injury & 0/2 (2 reop) & $0 / 1$ & $0 / 3(3.7)$ \\
\hline Sensory deficit & $0 / 0$ & $2 / 0$ & $2 / 0(2.4)$ \\
\hline Mental status change & $2 / 0$ & $0 / 0$ & $2 / 0(2.4)$ \\
\hline Stroke & $0 / 0$ & $0 / 1$ & $0 / 1(1.2)$ \\
\hline Operative & $18 / 1(23.2)$ & $0 / 0(0.0)$ & $18 / 1(23.2)$ \\
\hline Dural tear & $16 / 1$ & $0 / 0$ & $16 / 1(20.7)$ \\
\hline Pleural injury & $2 / 0$ & $0 / 0$ & $2 / 0(2.4)$ \\
\hline Cardiopulmonary & 9/8 (20.7) & $1 / 1(2.4)$ & 10/9 (23.2) \\
\hline Pleural effusion & $6 / 0$ & $1 / 0$ & $7 / 0(8.5)$ \\
\hline Pulmonary embolism & $0 / 3$ & $0 / 0$ & $0 / 3(3.7)$ \\
\hline $\begin{array}{l}\text { Deep venous throm- } \\
\text { bosis }\end{array}$ & $0 / 3$ & $0 / 0$ & $0 / 3(3.7)$ \\
\hline Arrhythmia & $1 / 1$ & $0 / 0$ & $1 / 1(2.4)$ \\
\hline $\begin{array}{l}\text { Congestive heart } \\
\text { failure }\end{array}$ & $0 / 1$ & $0 / 1$ & $0 / 2(2.4)$ \\
\hline Vascular edema & $1 / 0$ & $0 / 0$ & $1 / 0(1.2)$ \\
\hline Other & $1 / 0$ & $0 / 0$ & $1 / 0(1.2)$ \\
\hline Radiographic & $1 / 3(4.9)$ & $4 / 10(17.1)$ & $5 / 13(22.0)$ \\
\hline PJK & 0/3 (2 reop) & 1/4 (4 reop) & $1 / 7(9.8)$ \\
\hline Pseudarthrosis & $0 / 0$ & 0/4 (4 reop) & $0 / 4(4.9)$ \\
\hline $\begin{array}{l}\text { Global sagittal mal- } \\
\text { alignment }\end{array}$ & $1 / 0$ & 2/1 (1 reop) & $3 / 1(4.9)$ \\
\hline $\begin{array}{l}\text { Global coronal mal- } \\
\text { alignment }\end{array}$ & $0 / 0$ & 0/1 (1 reop) & $0 / 1(1.2)$ \\
\hline $\begin{array}{l}\text { Adjacent segment } \\
\text { disease }\end{array}$ & $0 / 0$ & $1 / 0$ & $1 / 0(1.2)$ \\
\hline Infection & $2 / 6(9.8)$ & $2 / 3(6.1)$ & $4 / 9(15.9)$ \\
\hline Deep wound infection & 0/4 (13 reop) & 0/2 (2 reop) & $0 / 6(7.3)$ \\
\hline Urinary tract infection & $1 / 0$ & $1 / 0$ & $2 / 0(2.4)$ \\
\hline Pneumonia & $0 / 1$ & $0 / 0$ & $0 / 1(1.2)$ \\
\hline $\begin{array}{l}\text { Superficial wound } \\
\text { infection }\end{array}$ & 0/1 (1 reop) & $0 / 0$ & $0 / 1(1.2)$ \\
\hline Sepsis & $0 / 0$ & $0 / 1$ & $0 / 1(1.2)$ \\
\hline Clostridium difficile & $1 / 0$ & $1 / 0$ & $2 / 0(2.4)$ \\
\hline
\end{tabular}

CONTINUED IN NEXT COLUMN »
» CONTINUED FROM PREVIOUS COLUMN

TABLE 3. Rates of complications in 82 adults with surgical treatment that included a 3-column osteotomy for spinal deformity with 2-year follow-up*

\begin{tabular}{|c|c|c|c|}
\hline \multirow[b]{2}{*}{$\begin{array}{c}\text { Complication } \\
\text { Category }\end{array}$} & \multicolumn{3}{|c|}{ No. of Complications, Major/Minor (\%) } \\
\hline & $\begin{array}{c}\text { Early } \\
\text { ( } \leq 6 \text { wks) }\end{array}$ & $\begin{array}{l}\text { Delayed } \\
\text { (>6 wks) }\end{array}$ & Total \\
\hline $\begin{array}{l}\text { Wound (excluding infec- } \\
\text { tion) }\end{array}$ & $4 / 3(8.5)$ & $0 / 3(3.7)$ & $4 / 6(12.2)$ \\
\hline Dehiscence & $1 / 2$ (2 reop) & 0/3 (3 reop) & $1 / 5(7.3)$ \\
\hline Erythema & $1 / 0$ & $0 / 0$ & $1 / 0(1.2)$ \\
\hline Hematoma/seroma & 2/1 (1 reop) & $0 / 0$ & $2 / 1(3.7)$ \\
\hline Gastrointestinal & $3 / 0(3.7)$ & $1 / 0(1.2)$ & $4 / 0(4.9)$ \\
\hline lleus & $3 / 0$ & $1 / 0$ & $4 / 0(4.9)$ \\
\hline Vascular & $2 / 0(2.4)$ & $0 / 0(0.0)$ & $2 / 0(2.4)$ \\
\hline Coagulopathy & $2 / 0$ & $0 / 0$ & $2 / 0(2.4)$ \\
\hline
\end{tabular}

* The number of reoperations indicates the subset of indicated major complications that were associated with the need for reoperation.

er complications, including implant prominence, screw nerve impingement, radiculopathy, motor deficit, nerve root injury, pleural injury, dural tear, and coronal imbalance, may be more influenced by operative technique rather than by patient age. In addition, the multirevision status of many patients who are ultimately treated with a $3 \mathrm{CO}$ may introduce a risk of deep wound infection that exceeds the added risk of this complication that may be expected with increased age. Thus, while older patients may be expected to face greater risks of medical complications, the dominant complications in the present series were operative, and the occurrence of these complications may not be primarily driven by patient age.

Documentation and assessment of complications provides a powerful means by which to develop techniques and approaches to reduce the occurrence of specific complications. In the present study, the most common complications included rod breakage, motor deficit, PJK, and deep wound infection. Even since the time of enrollment into the study database, our group and others have been actively developing and applying techniques to reduce many of these complications. There are several examples of these advancements. Among patients treated with $3 \mathrm{CO}$, rod fracture has been reported to most commonly occur at or adjacent to the level of the $3 \mathrm{CO},{ }^{58,62,64}$ which has prompted application of supplemental shorter rods to span the osteotomy level. ${ }^{27,28}$ Gupta and colleagues recently reported a novel technique that utilizes 4 rods spanning the $3 \mathrm{CO}$ level and includes 2 independent rods that attach only to the vertebral levels immediately adjacent to the $3 \mathrm{CO}$ (unpublished data). This technique was reported to reduce the rod fracture rate from $25 \%$ to $0 \%$. The most common radiographic complication and a common reason for reoperation in the present series was PJK. Advancements in our understanding of optimal radiographic alignment are promising in helping reduce this complication, $, 25,35,38,51$ and a classification has been developed to better appreciate factors associated with the need for revision surgery for PJK. ${ }^{36}$ In addition, a recent report from Bess and colleagues 
TABLE 4. Comparison between patients who did and did not sustain early or delayed complications based on demographic and surgical parameters

\begin{tabular}{|c|c|c|c|c|c|c|}
\hline \multirow[b]{2}{*}{ Parameter } & \multicolumn{3}{|c|}{ Early Complication? } & \multicolumn{3}{|c|}{ Delayed Complication? } \\
\hline & No & Yes & $\mathrm{p}$ Value & No & Yes & p Value \\
\hline Mean age (SD) & $61.7(12.0)$ & $60.0(11.4)$ & 0.50 & $62.0(12.2)$ & $59.9(11.3)$ & 0.41 \\
\hline Female (\%) & 53.2 & 46.8 & 0.22 & 48.4 & 51.6 & 0.22 \\
\hline Mean BMI (SD) & $29.2(6.5)$ & $28.9(5.4)$ & 0.83 & $27.7(6.4)$ & $30.1(5.4)$ & 0.06 \\
\hline Mean CCl (SD) & $1.7(1.4)$ & $2.5(2.2)$ & 0.10 & $1.9(1.8)$ & $2.3(2.0)$ & 0.47 \\
\hline Mean ASA (SD) & $2.6(0.6)$ & $2.6(0.5)$ & 0.93 & $2.5(0.6)$ & $2.6(0.5)$ & 0.69 \\
\hline Current smoker (\%) & 50.0 & 50.0 & 0.73 & 0.0 & 100.0 & 0.31 \\
\hline Previous spine surgery (\%) & 53.9 & 47.1 & 0.18 & 41.4 & 58.6 & 0.09 \\
\hline Previous spine fusion (\%) & 51.6 & 48.4 & 0.23 & 43.8 & 56.2 & 0.27 \\
\hline PSO (not VCR) & 54.4 & 45.6 & 0.07 & 47.1 & 52.9 & 0.32 \\
\hline
\end{tabular}

PSO = pedicle subtraction osteotomy; VCR = vertebral column resection.

Early complications were defined as those that occurred within 6 weeks of surgery. Delayed complications were defined as those that occurred within the first 2 years of follow-up and more than 6 weeks after surgery.

suggests that posterior polyethylene tethers at the proximal junction may reduce the stress at the junctional level and in turn may reduce the risk of PJK. Infections accounted for $11 \%$ of all major complications, and deep wound infection was the most common infection. Multiple publications have suggested that the use of intrawound vancomycin powder may reduce the occurrence of deep wound infections. ${ }^{30,66}$ Major deformity surgeries have inherent risks of neurological deficits, and perioperative use of the drug riluzole, which modulates excitatory neurotransmission, is being explored as a protective measure for neurological complications. ${ }^{1,24,31,32,69}$ In addition, advances in less inva- sive techniques, including the "mini-open PSO"70 and the use of lateral approaches with anterior column release, ${ }^{68}$ may help to reduce overall complication rates associated with the treatment of this patient population.

It remains controversial whether blood loss in spine surgery without apparent sequelae should be considered a direct complication and if so at what threshold it should be considered a complication. Nevertheless, it is important to recognize that substantial blood loss can be associated with complications such as hypotension, end organ damage, and coagulopathy. In addition, allogenic blood transfusions may introduce additional risks, including hemo-

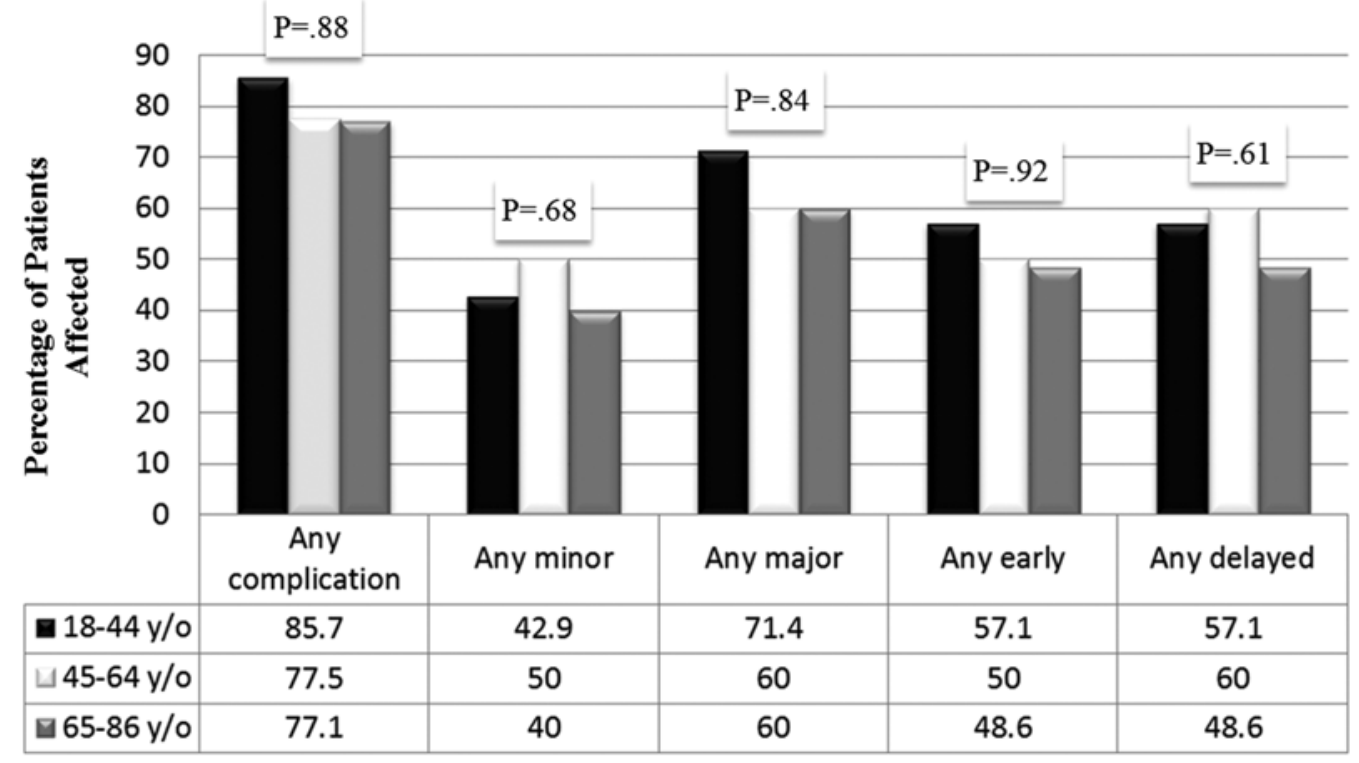

\section{Type of Complication}

FIG. 4. Distribution of 82 adults surgically treated with a $3 \mathrm{CO}$ for spinal deformity with 2-year follow-up stratified based on age group and by percentages of patients affected by any complication and by any minor, major, early (within 6 weeks of surgery), or delayed (between 6 weeks after surgery and last follow-up) complications. The $p$ values shown reflect comparisons of all 3 age groups. 


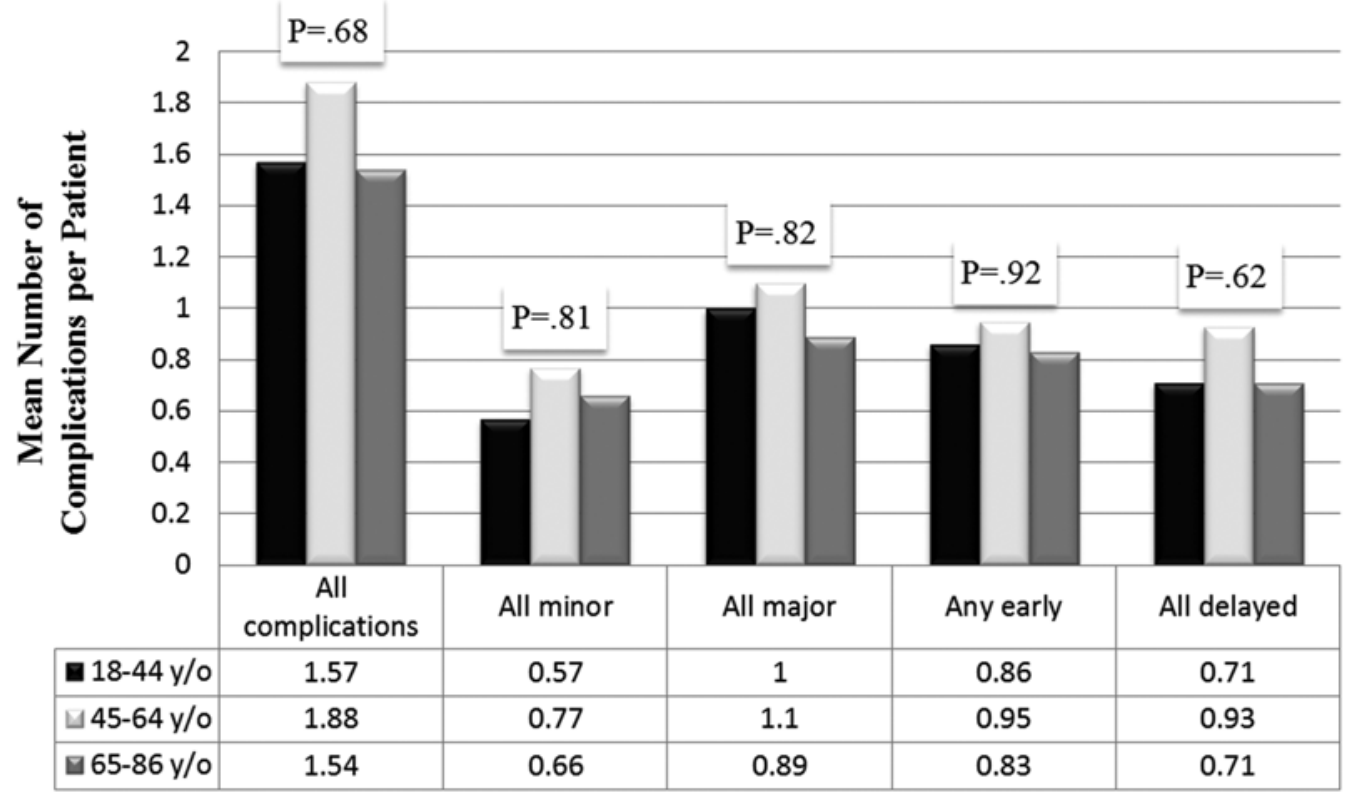

\section{Type of Complication}

FIG. 5. Mean numbers of complications per patient (all, minor, major, early [within 6 weeks of surgery], and delayed [between 6 weeks after surgery and last follow-up]) for 82 adults surgically treated with a $3 \mathrm{CO}$ for spinal deformity with 2-year follow-up stratified based on age group. y/o = years old. The $p$ values shown reflect comparisons of all 3 age groups.

lytic transfusion reactions, transfusion-related acute lung injuries, infection transmission, and immune modulation effects..$^{19}$ Even though in the present study there were no reported complications that were attributed to blood loss, it remains important to minimize the amount of blood $\operatorname{loss}^{67}$ and critically important to have an effective anesthesia team for resuscitation. The effectiveness of intraoperative antifibrinolytic therapy in significantly reducing blood loss has been suggested by several recent reports. $19,22,44,45,71$

Two-year follow-up was achieved for $77 \%$ of patients in the present study, which is comparable to previous reports of outcomes for ASD surgery. ${ }^{12,59-61}$ Among the 24 patients who did not achieve 2-year follow-up, there were no known deaths. The reasons why these patients did not complete 2-year follow-up are unknown. To assess whether the lack of follow-up may relate to the occurrence of complications, we have provided a separate summary of the early and delayed complications for these patients. The types and overall rates of early complications were similar between those that did and did not achieve 2-year followup, and there did not appear to be an inordinate number or representation of particularly severe delayed complications in the patients lost to follow-up. Thus, it does not appear that that occurrence of complications is a primary factor for lack of patient follow-up.

Strengths of the present study include the prospective multicenter design for data collection, use of standardized data collection sheets, presence of on-site study coordinators, regular auditing of data, and the length of follow-up. Despite the prospective collection of data, the primary limitation of the present study is the retrospective design of the analysis, which could lead to underestimation of complication rates and potentially impact the assessment of associations between complication rates and clinical parameters. In addition the study design had limited ability to detect some occult complications. For example, since many sites do not obtain routine CT imaging at followup, assessment of complications such as medial screw breaches and pseudarthrosis was limited to the clinically significant cases. The limited number of patients treated with more than one $3 \mathrm{CO}$ did not enable a meaningful subanalysis of this patient group with regard to complication rates. Although we have endeavored to be as complete as possible with regard to the occurrence of complications in all patients in our data set, including those who did not achieve 2-year follow-up, it is possible that patients lost to follow-up may have experienced additional complications after their last study follow-up visit. This limitation should be considered when assessing the complications in those lost to follow-up and in comparing these complications and rates to those for patients with complete 2-year followup. In addition, in the present study we do not provide assessment of complication impact on patient outcomes, as this is beyond the scope of the present study and will be the subject of future efforts.

\section{Conclusions}

This study provides an assessment of the complications associated with surgery for ASD that included $3 \mathrm{CO}$ based on cases derived from a prospective, multicenter database with 2-year follow-up. Among 82 patients, a total of 76 early complications (44 minor and 32 major) were documented, and $50.0 \%$ of patients were affected by one or more of these complications. A total of 66 delayed compli- 
TABLE 5. Rates of complications in 24 adults who underwent surgical treatment that included a 3-column osteotomy for spinal deformity and did not achieve 2-year follow-up*

\begin{tabular}{lccc}
\hline & $\begin{array}{c}\text { Complication } \\
\text { Category }\end{array}$ & No. of Complications, Major/Minor (\%) & Total \\
\cline { 2 - 4 } Operative & $5 / 0(20.8)$ & $0 / 0(0.0)$ & $5 / 0(20.8)$ \\
\hline Implant & $0 / 0(0.0)$ & $0 / 5(20.8)$ & $0 / 5(20.8)$ \\
\hline Radiographic & $0 / 0(0.0)$ & $1 / 4(20.8)$ & $1 / 4(20.8)$ \\
\hline Neurologic & $0 / 0(0.0)$ & $0 / 0(0.0)$ & $0 / 0(0.0)$ \\
\hline Infection & $1 / 1(8.3)$ & $1 / 2(12.5)$ & $2 / 3(20.8)$ \\
\hline Cardiopulmonary & $0 / 0(0.0)$ & $0 / 0(0.0)$ & $0 / 0(0.0)$ \\
\hline Wound (excluding infection) & $0 / 0(0.0)$ & $0 / 0(0.0)$ & $0 / 0(0.0)$ \\
\hline Gastrointestinal & $2 / 1(12.5)$ & $0 / 0(0.0)$ & $2 / 1(12.5)$ \\
\hline Vascular & $0 / 0(0.0)$ & $0 / 0(0.0)$ & $0 / 0(0.0)$ \\
\hline Total (minor/major) & $10(8 / 2)$ & $13(2 / 11)$ & $23(10 / 13)$ \\
\hline Mean no. of complications/patient (minor/major) & $0.42(0.33 / 0.08)$ & $0.54(0.08 / 0.46)$ & $0.96(0.42 / 0.54)$ \\
\hline No. of patients affected (\%) & $10(41.7)$ & $10(41.7)$ & $14(58.3)$ \\
\hline
\end{tabular}

* The mean duration of follow-up for these 24 patients was 0.85 years. No follow-up beyond discharge was reported for 3 patients, 7 additional patients had no follow-up beyond 6 weeks, and 14 had no follow-up beyond 1 year.

cations were reported (13 minor, 53 major), and $54.9 \%$ of patients had one or more of these complications. The most common complications were rod breakage, motor deficit, PJK, and deep wound infection. This study represents one of the most complete and detailed reports to date of early and delayed complications associated with surgical treatment for ASD that includes 3CO. These findings may prove useful for treatment planning, patient counseling, benchmarking of complication rates, and ongoing efforts to improve the safety of patient care.

\section{References}

1. Ahuja CS, Martin AR, Fehlings M: Recent advances in managing a spinal cord injury secondary to trauma. F1000 Res 5:5, 2016

2. Ames CP, Smith JS, Scheer JK, Bess S, Bederman SS, Deviren $\mathrm{V}$, et al: Impact of spinopelvic alignment on decision making in deformity surgery in adults: A review. J Neurosurg Spine 16:547-564, 2012

3. Auerbach JD, Lenke LG, Bridwell KH, Sehn JK, Milby AH, Bumpass D, et al: Major complications and comparison between 3-column osteotomy techniques in 105 consecutive spinal deformity procedures. Spine (Phila Pa 1976) 37:1198-1210, 2012

4. Barrey C, Perrin G, Michel F, Vital JM, Obeid I: Pedicle subtraction osteotomy in the lumbar spine: indications, technical aspects, results and complications. Eur J Orthop Surg Traumatol 24 (Suppl 1):S21-S30, 2014

5. Barton C, Noshchenko A, Patel V, Cain C, Kleck C, Burger $\mathrm{E}$ : Risk factors for rod fracture after posterior correction of adult spinal deformity with osteotomy: a retrospective caseseries. Scoliosis 10:30, 2015

6. Berjano P, Aebi M: Pedicle subtraction osteotomies (PSO) in the lumbar spine for sagittal deformities. Eur Spine J 24 (Suppl 1):S49-S57, 2015

7. Bess S, Harris JE, Turner AW, LaFage V, Smith JS, Shaffrey CI, et al: The effect of posterior polyester tethers on the biomechanics of proximal junctional kyphosis: a finite element analysis. J Neurosurg Spine [epub ahead of print September 9, 2016. DOI: 10.3171/2016.6.SPINE151477]
8. Bianco K, Norton R, Schwab F, Smith JS, Klineberg E, Obeid I, et al: Complications and intercenter variability of three-column osteotomies for spinal deformity surgery: a retrospective review of 423 patients. Neurosurg Focus 36(5):E18, 2014

9. Booth KC, Bridwell KH, Lenke LG, Baldus CR, Blanke KM: Complications and predictive factors for the successful treatment of flatback deformity (fixed sagittal imbalance). Spine (Phila Pa 1976) 24:1712-1720, 1999

10. Bridwell KH: Decision making regarding Smith-Petersen vs. pedicle subtraction osteotomy vs. vertebral column resection for spinal deformity. Spine (Phila Pa 1976) 31 (19 Suppl):S171-S178, 2006

11. Bridwell KH, Baldus C, Berven S, Edwards C II, Glassman $\mathrm{S}$, Hamill C, et al: Changes in radiographic and clinical outcomes with primary treatment adult spinal deformity surgeries from two years to three- to five-years follow-up. Spine (Phila Pa 1976) 35:1849-1854, 2010

12. Bridwell KH, Glassman S, Horton W, Shaffrey C, Schwab F, Zebala LP, et al: Does treatment (nonoperative and operative) improve the two-year quality of life in patients with adult symptomatic lumbar scoliosis: a prospective multicenter evidence-based medicine study. Spine (Phila Pa 1976) 34:2171-2178, 2009

13. Bridwell KH, Lewis SJ, Edwards C, Lenke LG, Iffrig TM, Berra A, et al: Complications and outcomes of pedicle subtraction osteotomies for fixed sagittal imbalance. Spine (Phila Pa 1976) 28:2093-2101, 2003

14. Bridwell KH, Lewis SJ, Lenke LG, Baldus C, Blanke K: Pedicle subtraction osteotomy for the treatment of fixed sagittal imbalance. J Bone Joint Surg Am 85-A:454-463, 2003

15. Bridwell KH, Lewis SJ, Rinella A, Lenke LG, Baldus C, Blanke K: Pedicle subtraction osteotomy for the treatment of fixed sagittal imbalance. Surgical technique. J Bone Joint Surg Am 86-A (Suppl 1):44-50, 2004

16. Buchowski JM, Bridwell KH, Lenke LG, Kuhns CA, Lehman RA Jr, Kim YJ, et al: Neurologic complications of lumbar pedicle subtraction osteotomy: a 10-year assessment. Spine (Phila Pa 1976) 32:2245-2252, 2007

17. Champain S, Benchikh K, Nogier A, Mazel C, Guise JD, Skalli W: Validation of new clinical quantitative analysis software applicable in spine orthopaedic studies. Eur Spine J 15:982-991, 2006

18. Charlson ME, Pompei P, Ales KL, MacKenzie CR: A new 
method of classifying prognostic comorbidity in longitudinal studies: development and validation. J Chronic Dis 40:373383, 1987

19. Cheriyan T, Maier SP II, Bianco K, Slobodyanyuk K, Rattenni RN, Lafage V, et al: Efficacy of tranexamic acid on surgical bleeding in spine surgery: a meta-analysis. Spine J 15:752-761, 2015

20. Cho KJ, Kim KT, Kim WJ, Lee SH, Jung JH, Kim YT, et al: Pedicle subtraction osteotomy in elderly patients with degenerative sagittal imbalance. Spine (Phila Pa 1976) 38:E1561E1566, 2013

21. Cogniet A, Aunoble S, Rigal J, Demezon H, Sadikki R, Le Huec JC: Clinical and radiological outcomes of lumbar posterior subtraction osteotomies are correlated to pelvic incidence and FBI index: Prospective series of 63 cases. Eur Spine J 25:2657-2667, 2016

22. Cuellar JM, Yoo A, Tovar N, Coelho PG, Jimbo R, Vandeweghe S, et al: The effects of Amicar and TXA on lumbar spine fusion in an animal model. Spine (Phila Pa 1976) 39:E1132E1137, 2014

23. Dickson DD, Lenke LG, Bridwell KH, Koester LA: Risk factors for and assessment of symptomatic pseudarthrosis after lumbar pedicle subtraction osteotomy in adult spinal deformity. Spine (Phila Pa 1976) 39:1190-1195, 2014

24. Fehlings MG, Nakashima H, Nagoshi N, Chow DS, Grossman RG, Kopjar B: Rationale, design and critical end points for the Riluzole in Acute Spinal Cord Injury Study (RISCIS): a randomized, double-blinded, placebo-controlled parallel multi-center trial. Spinal Cord 54:8-15, 2016

25. Gupta M, Henry JK, Schwab F, Klineberg E, Smith JS, Gum JL, et al: Dedicated spino-pelvic measurement software quantifies key spino-pelvic parameters more reliably than traditional picture archiving and communication systems tools. Spine (Phila Pa 1976) 41:E22-E27, 2016

26. Gupta MC, Ferrero E, Mundis G, Smith JS, Shaffrey CI, Schwab F, et al: Pedicle subtraction osteotomy in the revision versus primary adult spinal deformity patient: is there a difference in correction and complications? Spine (Phila Pa 1976) 40:E1169-E1175, 2015

27. Hallager DW, Gehrchen M, Dahl B, Harris JA, Gudipally M, Jenkins S, et al: Use of supplemental short pre-contoured accessory rods and cobalt chrome alloy posterior rods reduces primary rod strain and range of motion across the pedicle subtraction osteotomy level: an in vitro biomechanical study. Spine (Phila Pa 1976) 41:E388-E395, 2016

28. Hyun SJ, Lenke LG, Kim YC, Koester LA, Blanke KM: Comparison of standard 2-rod constructs to multiple-rod constructs for fixation across 3-column spinal osteotomies. Spine (Phila Pa 1976) 39:1899-1904, 2014

29. Ikenaga M, Shikata J, Takemoto M, Tanaka C: Clinical outcomes and complications after pedicle subtraction osteotomy for correction of thoracolumbar kyphosis. J Neurosurg Spine 6:330-336, 2007

30. Kang DG, Holekamp TF, Wagner SC, Lehman RA Jr: Intrasite vancomycin powder for the prevention of surgical site infection in spine surgery: a systematic literature review. Spine J 15:762-770, 2015

31. Karadimas SK, Laliberte AM, Tetreault L, Chung YS, Arnold P, Foltz WD, et al: Riluzole blocks perioperative ischemia-reperfusion injury and enhances postdecompression outcomes in cervical spondylotic myelopathy. Sci Transl Med 7:316ra194, 2015

32. Kato S, Fehlings M: Degenerative cervical myelopathy. Curr Rev Musculoskelet Med 9:263-271, 2016

33. Kim YJ, Bridwell KH, Lenke LG, Cheh G, Baldus C: Results of lumbar pedicle subtraction osteotomies for fixed sagittal imbalance: a minimum 5-year follow-up study. Spine (Phila Pa 1976) 32:2189-2197, 2007

34. La Maida GA, Luceri F, Gallozzi F, Ferraro M, Bernardo
M: Complication rate in adult deformity surgical treatment: safety of the posterior osteotomies. Eur Spine J 24 (Suppl 7):879-886, 2015

35. Lafage R, Schwab F, Challier V, Henry JK, Gum J, Smith $\mathrm{J}$, et al: Defining spino-pelvic alignment thresholds: should operative goals in adult spinal deformity surgery account for age? Spine (Phila Pa 1976) 41:62-68, 2016

36. Lau D, Funao H, Clark AJ, Nicholls F, Smith JS, Bess S, et al: The clinical impact correlation of the Hart-ISSG proximal junctional kyphosis severity scale with health-related qualityof-life outcomes and need for revision surgery. Spine (Phila Pa 1976) 41:213-223, 2016

37. Lenke LG, Fehlings MG, Shaffrey CI, Cheung KM, Carreon L, Dekutoski MB, et al: Neurologic outcomes of complex adult spinal deformity surgery: results of the prospective, multicenter Scoli-RISK-1 study. Spine (Phila Pa 1976) 41:204-212, 2016

38. Maggio D, Ailon TT, Smith JS, Shaffrey CI, Lafage V, Schwab F, et al: Assessment of impact of standing longcassette radiographs on surgical planning for lumbar pathology: an international survey of spine surgeons. J Neurosurg Spine 23:581-588, 2015

39. McCarthy I, Hostin R, O'Brien M, Saigal R, Ames CP: Health economic analysis of adult deformity surgery. Neurosurg Clin N Am 24:293-304, 2013

40. McCarthy I, O'Brien M, Ames C, Robinson C, Errico T, Polly DW Jr, et al: Incremental cost-effectiveness of adult spinal deformity surgery: observed quality-adjusted life years with surgery compared with predicted quality-adjusted life years without surgery. Neurosurg Focus 36(5):E3, 2014

41. McCarthy IM, Hostin RA, Ames CP, Kim HJ, Smith JS, Boachie-Adjei O, et al: Total hospital costs of surgical treatment for adult spinal deformity: an extended follow-up study. Spine J 14:2326-2333, 2014

42. McCarthy IM, Hostin RA, O'Brien MF, Fleming NS, Ogola G, Kudyakov R, et al: Analysis of the direct cost of surgery for four diagnostic categories of adult spinal deformity. Spine J 13:1843-1848, 2013

43. O'Brien MF, Kuklo TR, Blanke KM, Lenke LG (eds): Spinal Deformity Study Group Radiographic Measurement Manual. Memphis: Medtronic Sofamor Danek, 2005

44. Peters A, Verma K, Slobodyanyuk K, Cheriyan T, Hoelscher C, Schwab F, et al: Antifibrinolytics reduce blood loss in adult spinal deformity surgery: a prospective, randomized controlled trial. Spine (Phila Pa 1976) 40:E443-E449, 2015

45. Raksakietisak M, Sathitkarnmanee B, Srisaen P, Duangrat T, Chinachoti T, Rushatamukayanunt P, et al: Two doses of tranexamic acid reduce blood transfusion in complex spine surgery: a prospective randomized study. Spine (Phila Pa 1976) 40:E1257-E1263, 2015

46. Rillardon L, Levassor N, Guigui P, Wodecki P, Cardinne L, Templier A, et al: [Validation of a tool to measure pelvic and spinal parameters of sagittal balance.] Rev Chir Orthop Reparatrice Appar Mot 89:218-227, 2003 (Fr)

47. Sansur CA, Smith JS, Coe JD, Glassman SD, Berven SH, Polly DW Jr, et al: Scoliosis Research Society morbidity and mortality of adult scoliosis surgery. Spine (Phila Pa 1976) 36:E593-E597, 2011

48. Scheer JK, Lafage V, Smith JS, Deviren V, Hostin R, McCarthy IM, et al: Impact of age on the likelihood of reaching a minimum clinically important difference in 374 three-column spinal osteotomies: clinical article. J Neurosurg Spine 20:306-312, 2014

49. Schwab F, Blondel B, Chay E, Demakakos J, Lenke L, Tropiano $\mathrm{P}$, et al: The comprehensive anatomical spinal osteotomy classification. Neurosurgery 76 (Suppl 1):S33-S41, 2015

50. Schwab F, Ungar B, Blondel B, Buchowski J, Coe J, Deinlein D, et al: Scoliosis Research Society-Schwab Adult Spinal 
Deformity Classification: a validation study. Spine (Phila Pa 1976) 37:1077-1082, 2012

51. Schwab FJ, Blondel B, Bess S, Hostin R, Shaffrey CI, Smith JS, et al: Radiographical spinopelvic parameters and disability in the setting of adult spinal deformity: a prospective multicenter analysis. Spine (Phila Pa 1976) 38:E803-E812, 2013

52. Smith JS, Bess S, Shaffrey CI, Burton DC, Hart RA, Hostin $\mathrm{R}$, et al: Dynamic changes of the pelvis and spine are key to predicting postoperative sagittal alignment after pedicle subtraction osteotomy: a critical analysis of preoperative planning techniques. Spine (Phila Pa 1976) 37:845-853, 2012

53. Smith JS, Kasliwal MK, Crawford A, Shaffrey CI: Outcomes, expectations, and complications overview for the surgical treatment of adult and pediatric spinal deformity. Spine Deformity [epub ahead of print], 2012

54. Smith JS, Klineberg E, Lafage V, Shaffrey CI, Schwab F, Lafage R, et al: Prospective multicenter assessment of perioperative and minimum 2-year postoperative complication rates associated with adult spinal deformity surgery. J Neurosurg Spine 25:1-14, 2016

55. Smith JS, Klineberg E, Schwab F, Shaffrey CI, Moal B, Ames CP, et al: Change in classification grade by the SRSSchwab Adult Spinal Deformity Classification predicts impact on health-related quality of life measures: prospective analysis of operative and nonoperative treatment. Spine (Phila Pa 1976) 38:1663-1671, 2013

56. Smith JS, Lafage V, Shaffrey CI, Schwab F, Lafage R, Hostin R, et al: Outcomes of operative and nonoperative treatment for adult spinal deformity: a prospective, multicenter, propensity-matched cohort assessment with minimum 2-year follow-up. Neurosurgery 78:851-861, 2016

57. Smith JS, Sansur CA, Donaldson WF III, Perra JH, Mudiyam R, Choma TJ, et al: Short-term morbidity and mortality associated with correction of thoracolumbar fixed sagittal plane deformity: a report from the Scoliosis Research Society Morbidity and Mortality Committee. Spine (Phila Pa 1976) 36:958-964, 2011

58. Smith JS, Shaffrey CI, Ames CP, Demakakos J, Fu KM, Keshavarzi S, et al: Assessment of symptomatic rod fracture after posterior instrumented fusion for adult spinal deformity. Neurosurgery 71:862-867, 2012

59. Smith JS, Shaffrey CI, Berven S, Glassman S, Hamill C, Horton W, et al: Improvement of back pain with operative and nonoperative treatment in adults with scoliosis. Neurosurgery 65:86-94, 2009

60. Smith JS, Shaffrey CI, Berven S, Glassman S, Hamill C, Horton W, et al: Operative versus nonoperative treatment of leg pain in adults with scoliosis: a retrospective review of a prospective multicenter database with two-year follow-up. Spine (Phila Pa 1976) 34:1693-1698, 2009

61. Smith JS, Shaffrey CI, Glassman SD, Berven SH, Schwab FJ, Hamill CL, et al: Risk-benefit assessment of surgery for adult scoliosis: an analysis based on patient age. Spine (Phila Pa 1976) 36:817-824, 2011

62. Smith JS, Shaffrey E, Klineberg E, Shaffrey CI, Lafage V, Schwab FJ, et al: Prospective multicenter assessment of risk factors for rod fracture following surgery for adult spinal deformity. J Neurosurg Spine 21:994-1003, 2014

63. Smith JS, Singh M, Klineberg E, Shaffrey CI, Lafage V, Schwab FJ, et al: Surgical treatment of pathological loss of lumbar lordosis (flatback) in patients with normal sagittal vertical axis achieves similar clinical improvement as surgical treatment of elevated sagittal vertical axis: clinical article. J Neurosurg Spine 21:160-170, 2014

64. Tang JA, Leasure JM, Smith JS, Buckley JM, Kondrashov D, Ames CP: Effect of severity of rod contour on posterior rod failure in the setting of lumbar pedicle subtraction osteotomy (PSO): a biomechanical study. Neurosurgery 72:276-283, 2013
65. Terran J, Schwab F, Shaffrey CI, Smith JS, Devos P, Ames CP, et al: The SRS-Schwab Adult Spinal Deformity Classification: assessment and clinical correlations based on a prospective operative and nonoperative cohort. Neurosurgery 73:559-568, 2013

66. Theologis AA, Demirkiran G, Callahan M, Pekmezci M, Ames C, Deviren V: Local intrawound vancomycin powder decreases the risk of surgical site infections in complex adult deformity reconstruction: a cost analysis. Spine (Phila Pa 1976) 39:1875-1880, 2014

67. Tse EY, Cheung WY, Ng KF, Luk KD: Reducing perioperative blood loss and allogeneic blood transfusion in patients undergoing major spine surgery. J Bone Joint Surg Am 93:1268-1277, 2011

68. Uribe JS, Smith DA, Dakwar E, Baaj AA, Mundis GM, Turner AW, et al: Lordosis restoration after anterior longitudinal ligament release and placement of lateral hyperlordotic interbody cages during the minimally invasive lateral transpsoas approach: a radiographic study in cadavers. J Neurosurg Spine 17:476-485, 2012

69. Vasconcelos NL, Gomes ED, Oliveira EP, Silva CJ, Lima R, Sousa N, et al: Combining neuroprotective agents: effect of riluzole and magnesium in a rat model of thoracic spinal cord injury. Spine J 16:1015-1024, 2016

70. Wang MY, Bordon G: Mini-open pedicle subtraction osteotomy as a treatment for severe adult spinal deformities: case series with initial clinical and radiographic outcomes. J Neurosurg Spine 24:769-776, 2016

71. Xie J, Lenke LG, Li T, Si Y, Zhao Z, Wang Y, et al: Preliminary investigation of high-dose tranexamic acid for controlling intraoperative blood loss in patients undergoing spine correction surgery. Spine J 15:647-654, 2015

72. Yeramaneni S, Robinson C, Hostin R: Impact of spine surgery complications on costs associated with management of adult spinal deformity. Curr Rev Musculoskelet Med 9:327-332, 2016

\section{Disclosures}

The International Spine Study Group (ISSG) is funded through research grants from DePuy-Synthes. Dr. Smith reports consultant relationships with Zimmer Biomet and NuVasive, receipt of clinical or research support for non-study-related effort as well as for the study described from DePuy Synthes, and fellowship funding from AOSpine and NREF. Dr. Shaffrey reports consultant relationships with Medtronic, NuVasive, Zimmer-Biomet, K2M, and Stryker; direct stock ownership in NuVasive; patent holder relationships with Medtronic, Nuvasive, and Zimmer-Biomet; and support of non-study-related clinical or research effort from DePuy-Synthes. Dr. Klineberg reports consultant relationships with DePuy-Synthes and Stryker and receipt of honoraria from $\mathrm{K} 2 \mathrm{M}$ and a spine fellowship grant from AOSpine. Dr. LeFage reports direct stock ownership in Nemaris, Inc.; a consultant relationship with NuVasive, Inc.; support of non-study-related clinical or research effort from NuVasive, Stryker, K2M, DePuy Spine (paid through ISSGF), and SRS; and speaking/teaching arrangements with K2M, MSD, Medicrea, NuVasive, and DePuy Spine. Dr. Schwab reports ownership in Nemaris Inc.; consultant and teaching/speaking relationships with Zimmer Biomet, Medicrea, NuVasive, K2M, and MSD; patent holder relationships with K2M and MSD; and support of non-study-related research or clinical effort from NuVasive, Stryker, K2M, and DePuy Spine (paid through ISSGF). Dr. Hostin reports a consultant relationship with DePuy-Synthes and receipt of clinical or research support for the study described from DePuy-Synthes, NuVasive, Seeger, DJO, and K2M. Dr. Mundis reports consultant relationships with NuVasive, $\mathrm{K} 2 \mathrm{M}$, and DePuy-Synthes and patent holder relationships with NuVasive and K2M. Dr. Gupta reports consultant relationships with DePuy, Medtronic, and Orthofix; receipt of royalties from DePuy; and direct stock ownership in Pfizer, Johnson \& John- 
son, and Proctor \& Gamble. Dr. Protopsaltis reports consultant relationships with Medicrea, Globus, and Innovasis and support for non-study-related clinical or research effort from Zimmer Biomet. Dr. Kelly reports grants/research support to his institution from OREF, Barnes Jewish Foundation, AOSpine, CSRS, Fox Family Foundation, Cerapedics, and PCORI. Dr. Deviren reports a consultant relationship with NuVasive, ownership in Guidepoint, and fellowship grant support paid to his institution from Globus, NuVasive, and AOSpine North America. Dr. Burton reports receipt of royalties and clinical or research support from DePuy for the study described. Dr. Bess reports consultant relationships with K2, NuVasive, and Allosource; patent holder relationships with K2 and Innovasis; and clinical or research support from DePuy-Synthes for the study described. Dr. Ames reports consultant relationships with Stryker, DePuy, and Medtronic; a patent holder relationship with Fish \& Richardson, P.C.; and receipt of royalties from Stryker and Biomet Spine.

\section{Author Contributions}

Conception and design: Smith, Klineberg, Schwab, Kim, Gupta, Protopsaltis, Kelly, Deviren, Hart, Burton, Bess, Ames. Acquisition of data: all authors. Analysis and interpretation of data: Smith, V Lafage, R Lafage, Scheer, Diebo. Drafting the article: Smith. Critically revising the article: all authors. Reviewed submitted version of manuscript: all authors. Approved the final version of the manuscript on behalf of all authors: Smith. Statistical analysis: Smith. Study supervision: Bess, Ames.

\section{Correspondence}

Justin S. Smith, Department of Neurosurgery, University of Virginia Health Sciences Center, Box 800212, Charlottesville, VA 22908.email: jss7f@virginia.edu. 